\title{
Ethical issues in Canadian gastroenterology: Results of a survey of Canadian gastroenterology trainees
}

\author{
Kenneth Malhotra MD, Clifford A Ottaway MD PhD FRCPC
}

\begin{abstract}
$\mathrm{K}$ Malhotra, CA Ottaway. Ethical issues in Canadian gastroenterology: Results of a survey of Canadian gastroenterology trainees. Can J Gastroenterol 2004;18(5):315-317.
\end{abstract}

BACKGROUND: Specialty-specific bioethical education is a mandated component of gastroenterology training programs in Canada, but no gastroenterology-specific bioethical curriculum is available. PURPOSE: To assess the relative importance of a variety of bioethical issues to the practice of gastroenterology.

METHOD: A convenience sample of Canadian gastroenterology residents and staff was surveyed at a national meeting for Canadian gastroenterology trainees. They were asked to indicate their opinions of the relative importance of 24 different bioethical issues in their practice of gastroenterology.

RESULTS: Respondents made distinctions in the relevance of different bioethical issues to the practice of gastroenterology and there was substantial concordance in the rankings indicated by residents and staff. Truth telling, consent and the capacity to give consent, and consent with regard to specific endoscopic procedures were ranked by both residents and staff as most important to their practice of gastroenterology. In contrast, the issue of euthanasia and assisted suicide was ranked near the bottom of the list by both residents and staff. The results differ in some respects from the key ethical questions identified by opinion leaders in gastroenterology.

INTERPRETATION: Gastroenterology residents and staff identify some topics as much more relevant than others to the practice of gastroenterology. It is proposed that this can provide a framework for developing a gastroenterology-specific bioethical curriculum, and that there is an important opportunity for developing a joint program through collaboration among gastroenterology training programs across Canada.

Key Words: Consent; Ethics; Gastroenterology training; Resident teaching

\section{L'éthique et la gastro-entérologie : résultats d'une enquête menée auprès de stagiaires en gastro-entérologie au Canada}

CONTEXTE : Les programmes de formation en gastro-entérologie au Canada doivent inclure des cours de bioéthique adaptés à la spécialité, mais il n'existe aucun programme propre au domaine au Canada.

BUT : Évaluer l'importance relative de certains problèmes de bioéthique liés à la pratique de la gastro-entérologie.

MÉTHODE : Un sondage a été mené auprès d'un échantillon de commodité, formé de résidents et résidentes et de membres du personnel, au cours d'une réunion nationale de stagiaires en gastro-entérologie au Canada. Nous leur avons demandé de donner leur opinion sur l'importance relative de 24 problèmes de bioéthique, applicables à leur domaine de pratique.

RÉSULTATS : Les répondants ont fait des distinctions quant à la pertinence des différents problèmes de bioéthique dans la pratique de la gastroentérologie, et il est ressorti un degré élevé de concordance entre le classement effectué par les résidents et celui indiqué par le personnel. Le fait de dire la vérité, l'obtention du consentement, la capacité de donner son consentement et les consentements relatifs à certaines interventions endoscopiques ont été jugés très importants dans la pratique de la gastroentérologie, et ce, tant par les résidents que par le personnel. En revanche, la question de l'euthanasie et du suicide assisté a été classée parmi les dernières, encore une fois par les deux groupes. Toutefois, des divergences sont apparues à certains égards en ce qui concerne les principaux problèmes d'éthique relevés par des guides d'opinion en gastro-entérologie. INTERPRÉTATION : Certains problèmes relatifs à la pratique de la gastro-entérologie ont été jugés beaucoup plus importants que d'autres par les résidents et résidentes ainsi que par les membres du personnel. Il s'agirait là, à notre avis, d'un bon point de départ pour l'élaboration d'un programme de bioéthique, propre au domaine. Ce serait également une excellente occasion de réunir des intervenants dans la formation en gastroentérologie au Canada pour concevoir un programme commun.
$\mathrm{T}$ he purpose of the present study was to assess the potential importance of various bioethical issues as they pertain to gastroenterology. The Royal College of Physicians and Surgeons of Canada expects candidates for the subspecialty examination in gastroenterology to "demonstrate an understanding of (their) ethical responsibilities" (1). Although there is no specified curriculum addressing the study of bioethics in Canadian gastroenterology programs, The Royal College of Physicians and Surgeons requires all residency training programs to include bioethics teaching as a condition of accreditation (2). Most trainees in gastroenterology will have been exposed to many aspects of bioethics during their curricula in medical school and in internal medicine before they start their gastroenterology training. With a view to initiating a framework that might be used to develop a more specific list of bioethical issues relevant to gastroenterology, we sought the opinions of Canadian gastroenterology trainees. A convenience sample of gastroenterology residents and gastroenterology staff at a national meeting for Canadian gastroenterology residents completed a questionnaire regarding the relevance of a variety of bioethical issues to the practice of gastroenterology.

\section{Department of Medicine, University of Toronto, Toronto, Ontario}

Correspondence and reprints: Dr Clifford A Ottaway, Gastroenterology, Room 16032, St Michael's Hospital, 30 Bond Street, Toronto, Ontario

M5B 1W8. Telephone 416-864-5684, fax 416-864-5882, e-mail ottawayc@smh.toronto.on.ca

Received for publication January 7, 2004. Accepted March 19, 2004 
TABLE 1

Ethics questionnaire distributed to sample population Please indicate your opinion of the importance of the following ethical issues in your practice of gastroenterology:

Advance care planning

Advance care planning in gastrointestinal malignancies

Advance care planning in hepatic failure

Advance care planning in portal hypertension

Conflict of interest in education

Conflict of interest in patient care

Conflict of interest in research

Consent and the capacity to give consent

Consent with regard to specific endoscopic procedures

Demands for inappropriate treatment

Ethics and artificial nutrition

Ethics and cultural and ethnic differences

Ethics and endoscopic training

Ethics and genetics

Ethics and the care of the pregnant woman

Ethics and transplantation

Euthanasia and assisted suicide

Involvement of children in medical decisions

Quality of end-of-life care

Resource allocation

Research ethics

Substitute decision-making

Truth telling and confidentiality

Voluntariness of consent

\section{METHODS}

A questionnaire (Table 1) was constructed based on topics discussed in the Canadian publication Bioethics at the Bedside (3) and in the Web site of the Royal College of Physicians and Surgeons of Canada (1). The questionnaire was distributed to attendees at a morning session of the Gastrointestinal Residents in Training program, which occurred during the Canadian Digestive Disease Week Conference in February 2001 at Banff, Alberta. Respondents were asked to indicate their opinion regarding the potential importance of 24 bioethical issues "in your practice of gastroenterology". Opinion for each issue was indicated by ranking on a five-point scale ranging from 'Not at all important' to 'Very important'. The questionnaire was distributed to all persons attending the session and they were asked to complete the survey during the five minutes following survey distribution. The responses were collected as attendees departed the room for a nutrition break. Each respondent was asked to indicate whether they were a gastroenterology trainee, a gastroenterology staff member of the conference faculty or other (eg, medical student, biology student). Responses $(n=13)$ from those who were neither gastroenterology trainees nor staff gastroenterologists were excluded from the analysis. The response rate was greater than $90 \%$, as judged by the list of attendees. The results were numerically coded by assigning a number from zero to five for each response. Zero indicated no response, one corresponded to 'Not at all important', two to 'Less than average importance', three to 'Average importance', four to 'Above average importance', and five to 'Very important'. Rank ordering for each of the 24 issues was calculated.

Other questions asked about the teaching of bioethics in the respondent's particular gastroenterology training program.

\section{RESULTS}

The questionnaire was completed by 43 gastroenterology trainees and nine gastroenterologists who were present as faculty for the course. Analysis of the data by rank order was used to separate the 10 issues ranked as of the highest importance (Table 2) and the five issues ranked as of the lowest importance (Table 3) for each group. Overall, there was substantial concordance between the rankings indicated by the residents and by the staff. Six of the issues identified as of highest importance by the gastrointestinal (GI) residents were also ranked within the top 10 by the GI staff (Table 2). Issues which were ranked among the highest 10 by the GI staff but not by GI residents included: conflict of interest in research, research ethics, ethics of endoscopic training, and ethics and genetics (Table 2). By contrast, the GI residents ranked ethics and transplantation, advance care planning in GI malignancies, ethics and the care of the pregnant woman, and the involvement of children in medical decisions within the most important 10 issues, whereas GI staff did not (Table 2).

Interestingly, the three lowest ranked issues were the same for both residents and staff (Table 3). The two most discordant results concerned advance care planning in GI malignancy and conflict of interest in research. The former issue was ranked seventh by GI residents but $20^{\text {th }}$ by GI staff, and conflict of interest in research was ranked $20^{\text {th }}$ by residents but fourth by GI staff (Tables 2,3).

In response to other questions, $65 \%$ of GI residents and $78 \%$ of GI staff indicated that ethical issues were addressed in their GI training programs. A substantial majority of both GI residents (93\%) and GI staff (100\%) indicated support for including education on ethical aspects of gastroenterology in GI training programs in Canada, and the majority (91\% of residents and $89 \%$ of staff) indicated that the case-based approach to ethical issues in GI was a preferred approach.

\section{DISCUSSION}

Both the gastroenterology residents and the gastroenterology staff surveyed here ranked the issues of truth telling and confidentiality, consent and capacity to give consent, and consent with respect to specific endoscopic procedures as the top three ethical issues of concern to their practice of gastroenterology. The three issues that were assigned the lowest ranks were the ethical aspects of artificial nutrition, euthanasia and assisted suicide, and voluntariness of consent. These results are interesting for at least two reasons. First, the respondents appear to recognize differences in the relevance of a variety of ethical issues to the practice of gastroenterology. Second, the opinions expressed here diverge from those expressed by some experts in the area.

Two authors have attempted to identify key ethical issues in GI practice. Sidorov (4) suggested three ethical areas of particular concern for gastroenterologists: artificial nutrition and hydration, training in GI endoscopy, and hepatic transplantation. More recently, Axon (5) highlighted the importance of four areas: medicalization of common conditions such as irritable bowel syndrome and gastroesophageal reflux; ethical concerns in screening as distinct from treatment in, for example, colorectal cancer; ethical limits of quality of care; and ethical aspects of endoscopic training. By necessity, these authors needed to make limited choices among ethical issues, but it is interesting to note that ethical aspects of training in endoscopy, which was identified as a major issue for each of 
TABLE 2

The 10 highest ranked ethical issues

\begin{tabular}{ll}
\hline GI residents $\mathbf{( n = 4 3 )}$ & GI staff (n=9) \\
\hline Truth telling and confidentiality & Consent with respect to specific endoscopic procedures \\
Consent and capacity to give consent & Consent and capacity to give consent \\
Consent with respect to specific endoscopic procedures & Truth telling and confidentiality \\
Ethics and transplantation & Conflict of interest in research \\
Quality of end-of-life care & Research ethics \\
Conflict of interest in patient care & Ethics of endoscopic training \\
Advance care planning in GI malignancies & Conflict of interest in patient care \\
Ethics and the care of the pregnant woman & Quality of end-of-life care \\
Advance care planning in hepatic failure & Advance care planning in hepatic failure \\
Involvement of children in medical decisions & Ethics and genetics
\end{tabular}

GI Gastrointestinal

TABLE 3

The five lowest ranked ethical issues

\begin{tabular}{ll}
\hline GI residents $(\mathbf{n}=\mathbf{4 3})$ & GI staff $(\mathbf{n}=\mathbf{9})$ \\
\hline Conflict of interest in research & Advance care planning in GI malignancies \\
Conflict of interest in education & Ethics and cultural and ethnic differences \\
Ethical aspects of artificial nutrition & Ethical aspects of artificial nutrition \\
Euthanasia and assisted suicide & Euthanasia and assisted suicide \\
Voluntariness of consent & Voluntariness of consent
\end{tabular}

GI Gastrointestinal

these authors, was highly ranked by the gastroenterology staff responding here. In contrast, ethical aspects of artificial nutrition was not ranked highly by either group of our respondents. In this regard, there are several reports (6-8) that suggest that adequacy of consent, identification of capacity and involvement of substitute decision makers in consent discussion are of particular concern in the placement of percutaneous endoscopic gastrostomy tubes for feeding.

It has been recommended that discipline-specific approaches to the teaching of ethics in Canadian subspecialty training programs are potentially the most effective format for achieving the goals of the Royal College (9), but little work has been done on the development of speciality-specific curriculae. Blackmer (10) reported on ethics teaching in Canadian physical medicine and rehabilitation programs and recommended that curriculum focused on the issues most likely to be encountered during daily specialty practice should be highlighted. The

\section{REFERENCES}

1. Royal College of Physicians and Surgeons of Canada. Information by specialty, objectives of training and training requirements. $<$ rcpsc.medical.org/information/index.php > (Version current at April 13, 2004).

2. Royal College of Physicians and Surgeons of Canada. Bioethics education <rcpsc.medical.org/ethics $>$ (Version current at April 13, 2004).

3. Singer PA, ed. Bioethics at the Bedside. Ottawa: Canadian Medical Association, 1999.

4. Sidorov JJ. Ethical dilemmas in gastroenterology. Med N Am 1995:472-6.

5. Axon A. Ethical considerations in gastroenterology and endoscopy. Dig Dis 2002;20:220-5. results reported here show that residents and staff gastroenterologists identify some ethical issues as more directly relevant to daily GI practice than others.

It is recognized that teaching time opportunities are severely constrained in gastroenterology training programs. Most programs are likely to have only a limited number of hours per year to dedicate to ethical issues. A first approximation to a practical curriculum for gastroenterology training programs could be achieved by directing attention to the topics identified in Table 2. It is also likely that not all gastroenterology training programs in Canada will have the resources and the staff to mount a comprehensive gastroenterology-specific ethics curriculum individually. Thus, this could represent an important opportunity for the cooperative development of a joint program involving multiple training sites, which may provide a more complete gastroenterology-specific bioethics curriculum for all gastroenterology residents.

6. Brett AS, Rosenberg JC. The adequacy of informed consent for the placement of gastrostomy tubes. Arch Intern Med 2001;161:745-8.

7. Bourne D. Informed consent and the placement of percutaneous endoscopic gastrostomy tubes. JAMA 2001;161:2506.

8. Ladas SD, Triantafyllou K, Liappas I, et al. Percutaneous endoscopic gastrostomy: Adequacy and quality of information given to decisionmakers. Dig Dis 2002;20:289-92.

9. McKneally MF, Singer PA. Bioethics for clinicians 25. Teaching bioethics in the clinical setting. CMAJ 2001;164:1163-7.

10. Blackmer J. Medical ethics teaching in Canadian physical medicine and rehabilitation programs. Annals RCPSC 2002;35:574-8. 


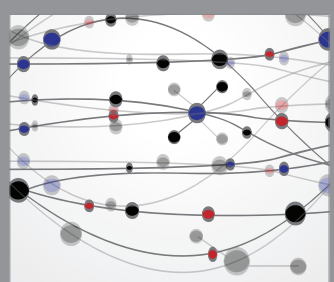

The Scientific World Journal
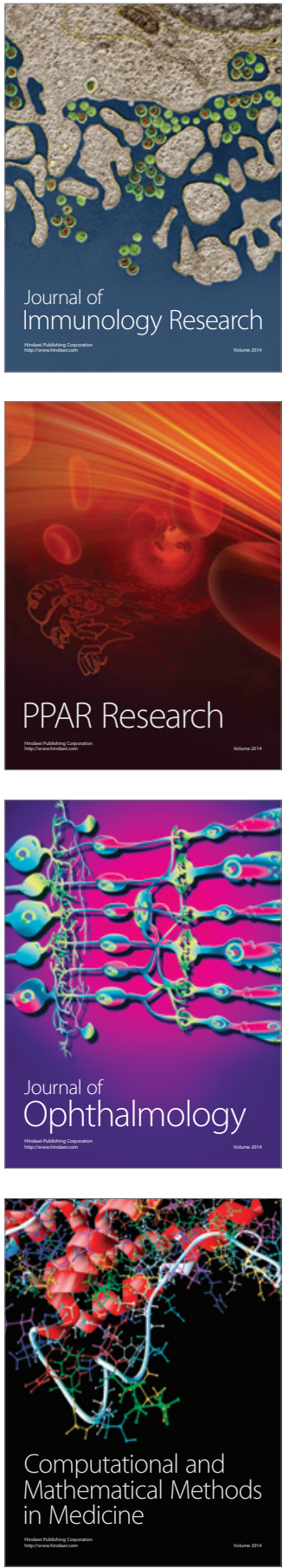

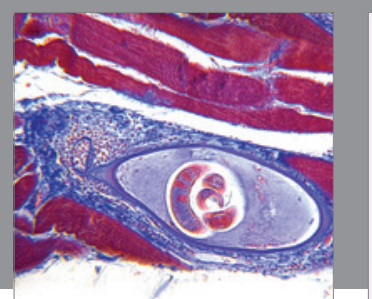

Gastroenterology Research and Practice

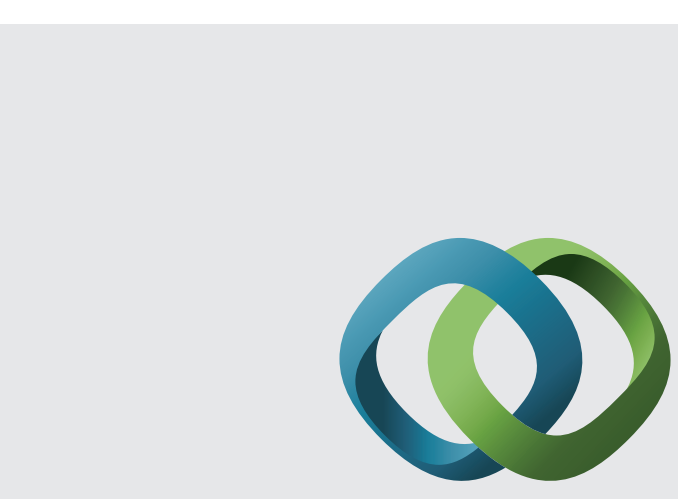

\section{Hindawi}

Submit your manuscripts at

http://www.hindawi.com
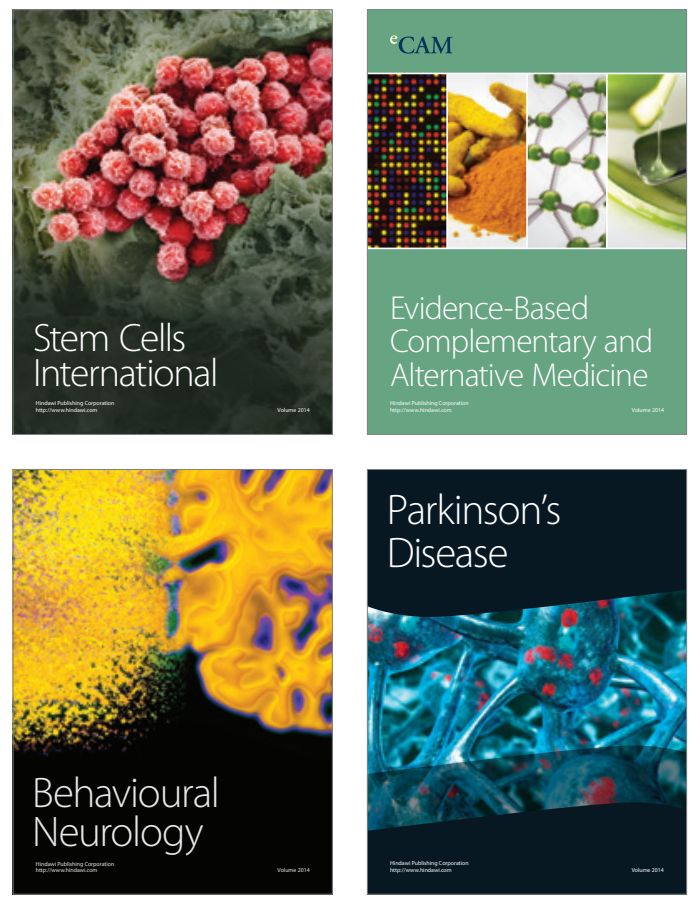
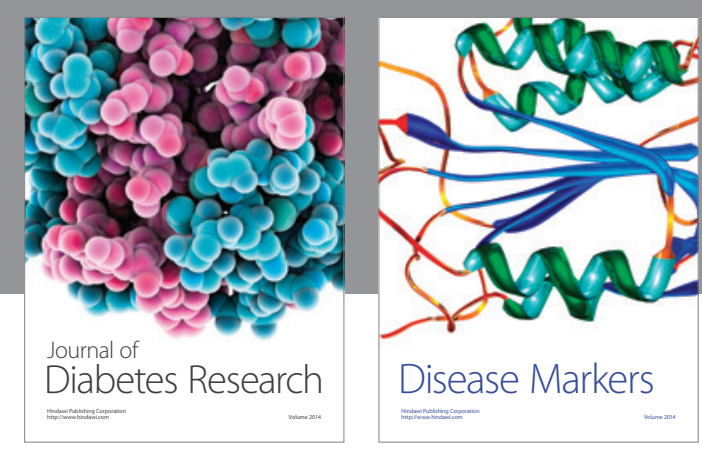

Disease Markers
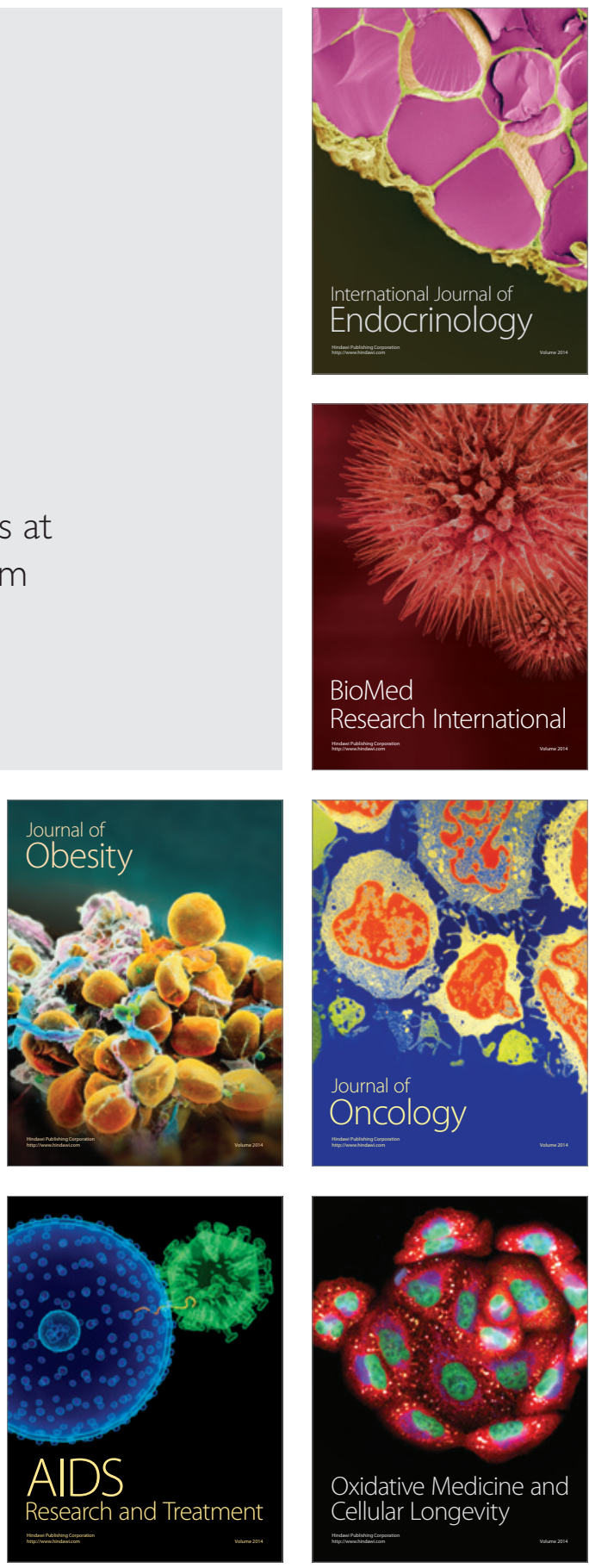